\title{
The Modern Retail Habitats in the Gulf Region: The Experience of the Bahraini Shopper
}

\author{
Jaafar A. M. Al-Mahy ${ }^{1}$ \\ ${ }^{1}$ College of Business Administration, University of Bahrain, Bahrain \\ Correspondence: Jaafar A. M. Al-Mahy, Department of Management and Marketing, College of Business \\ Administration, University of Bahrain, Al-Sakheer, P. O. Box 32038, Bahrain. Tel: 973-9354-6552. E-mail: \\ sudan1954.ja@gmail.com
}

Received: April 24, 2013

Accepted: May 20, 2013

Online Published: June 21, 2013

doi:10.5539/ijbm.v8n13p161

URL: http://dx.doi.org/10.5539/ijbm.v8n13p161

\begin{abstract}
This research paper explores the motives people go shopping in the Gulf region. The venue for the study is the Kingdom of Bahrain. The study sets out to test a major hypothesis that given the novelty of the modern retailing formats in the region; shoppers are more likely to stress the hedonic and social aspects of shopping than the utilitarian facets of it. Data was collected from a sample of Bahraini shoppers who answered specific questions pertaining to their shopping experience. The results obtained verified the research hypotheses. Respondents perception of shopping appears to be conditioned by two main factors; the novelty of the retail habitats and the harsh desert climate of the region. The topic of shopping motivation has important implications for retail management. It significantly impacts store design and layout, customers' loyalty, satisfaction, and store patronage.
\end{abstract}

Keywords: shopping motivation, hedonic motivation, utilitarian motivation, novelty, modern retailing formats, demographic characteristics

\section{Introduction}

The phenomenal expansion that the retail sector of the Gulf Co-operation Council countries (GCC) is currently undergoing is nothing short of a revolution. As a result of it the retailing landscape in these countries is being transformed beyond recognition. The traditional stand-alone stores and bazaars are gradually being replaced by a vibrant modern retail sector that parallels any in North America, Europe or Asia. Large scale retail formats such as supermarkets, specialty stores, chain stores, department stores, hypermarkets and other discounters have mushroomed in a record time throughout the region and in all directions. The main drivers that have contributed to this boom are: growing affluence and disposable incomes, a rise in tourism, a large expatriate population, a young demographic profile that acts as a robust demand booster and large scale infrastructure developments (Alpen, Capital, 2011).

Nowhere is this revolution more obvious, than in the kingdom of Bahrain. Historically, the dominant retail format in the country was the small independent cold store selling mainly groceries to customers. Gradually, the retail sector has undergone a radical facelift. An array of the state-of-the-art malls and shopping centers decorate the country's landscape nowadays. This remarkable journey began 25 years ago with the introduction of Yateem Center in the Souq at the heart of Manama, the Capital City. For the first time in Bahrain, the center offered its shoppers a closed air-conditioned shopping environment, covered car-parking, and a wide assortment of international brands under one roof. Since then, tens of malls and modem retail habitats have been built in all parts of the country.

Among the notable significant additions to the Bahrain retail scene, however, was the Seef Mall (1997). By any measure this is truly a regional mega mall; a shopping magnet drawing customers from all over Bahrain, Saudi Arabia and beyond. It houses 220 retail outlets, four large department stores, including BHs, Debenhams, Marks \& Spencer and Toys-R-Us, two food courts, a children entertainment center and two cinema complexes.

By the beginning of the new millennia, the rate of expansion of Bahrain retail sector gathered pace. A number of new malls were added to the array of malls in the Kingdom. Chief among these are the Bahrain (2000) and Dana Malls (2002). The Bahrain mall harbors 120 retailers including the hugely popular French-based Gean hypermarket, in addition to a play area for kids, a huge food court, banking and other attractions. With that in 
mind, the mall offers a true one-stop shopping experience and has managed to cultivate an image as a family-destination shopping venue. The Dana Mall anchors the popular Lulu hypermarket and a number of attractions like the Chaka zoo city, a food court, a large parking lot and a state-of-the-art cinema complex.

The jewel in the crown of Bahrain's retail sector, however, must be the gigantic Bahrain City Center (2008). This is by far the biggest shopping mall not only in Bahrain but possibly in the gulf region as well. The center includes a huge shopping area with 400 hundred retail stores. Among these is the first Carrefour hypermarket in Bahrain, a 20 screen cinema, a large indoor water park and a host of other attractions and facilities.

There are now over twenty malls and a similar number of super/hypermarkets in Bahrain. 25 years ago very few, if any of these existed. For a country with a population of just over one million, these numbers seem impressive.

The picture does not change much when one looks at other GCC countries. Some massive and new retail projects can be seen in all countries within the Gulf region; especially in Saudi Arabia and the United Arab emirates. Statistics bear witness to this unparalleled growth in the region's retail sector. In 2010, for instance, there were over 30000 retail units in the GCC and 10.3 million sq $\mathrm{m}$ of completed shopping centers. Today, the region has over 200 shopping malls with an annual sale of US \$ 50 billion (Alpen, Capital, 2010).

\subsection{Questions and Objectives of the Study}

The emergence of these modern shopping formats on the retail scene in the region has resulted in shopping becoming one of the major leisure activities for so many people and it is bound to have a significant impact on the shopping experience and the reasons people go shopping. At the very least it would color their views and perceptions of shopping. How do people in Bahrain view and perceive their shopping experience? What is the nature of such experience? What factors bear on it? These are all pertinent research questions that are worthy of academic study and investigation. So far, little research is done to explore these questions. This research project is an endeavor to rectify this situation and should, therefore, be seen as an effort to fill-in this knowledge vacuum regarding an important area such as shopping motivation. The specific objectives of this study, therefore, are:

a) To explore the reasons (motives) people go shopping in the Kingdom of Bahrain.

b) Determine whether these reasons (motives) are mainly related to the acquisition of products per se (utilitarian) or to the shopping experience itself (hedonic).

c) Relate these reasons (motives) to the demographic, social, and climatic contexts of shoppers.

\subsection{Shopping Motivation}

The notion of shopping motivation embedded in the question "why do people shop?" (Tauber, 1972) has stirred considerable academic interest in the last several decades. This is due to the obvious theoretical and practical managerial implications that the notion poses (Jones et al., 2003; Carpenter, 2008).

Motivation is the driving force within individuals that impels them to action (Schifman and Kanook, 2010). Most human behavior, in this sense, is purposive and goal-directed (Huczynski \& Buchanan, 2010). Few human behaviors are as purposeful as shopping (Puccinelli, et al., 2009). Understanding shopping motivation entails, therefore, exploring the reasons people go shopping (Ratneshwar et al., 2000). Available literature on the subject seems to suggest two typologies of shoppers; utilitarian and hedonic (Babin, et al., 1994).

The utilitarian shopper exhibits and prefers mere utility out of his/her shopping experience (Merriam-Webster, 2012). This shopping orientation approximates the classical economic model of consumer behavior and depicts the buyer as problem-solver, rational, and task-oriented (Batra \& Ahtola, 1991). The utilitarian shopping value is realized when the needed product is obtained and is increased if the product is obtained more effortlessly (Babin et al., 1994). Shopping here is approached with a work-like mentality and often described using terms reserved to evaluate work performance i.e. success, accomplishment, relief, and happy to go through it all (Hirschman and Holbrook, 1982).

Several writers, however, have since come out to challenge the economic model of consumer behavior. According to these writers, there is more to shopping than the mere acquisition of physical products; that people shop for various reasons which include not only utilitarian but hedonic reasons as well (Tauber, 1972; Hirschman and Holbrook, 1982; Babin et al., 1994; Cox et al. Arnold and Reynolds, 2003). Tauber (1972), for instance, argue that, "people's motives for shopping are a function of many variables, some of which are unrelated to the actual buying of products". As such, "an understanding of shopping motives requires the consideration of satisfaction which shopping activities provide, as well as the utility obtained from the merchandise that may be purchased” (1972, p. 46). In other words, the numerous intangible and emotional costs 
and benefits of shopping trips need to be recognized to understand the consumption activity fully (Holbrook, 1984). That is because, "the behavior of consumers is far more sensory complex, imaginative and emotion laden than have been reflected in the traditional approach, (Hirschman and Holbrook, 1982:100). Along the same line of argument, Babin et al. maintain that, "a strictly objective approach focusing on an object, its price, or the functional utility provided by that object, may be too narrow to account for all values provided by consumption experiences" (1994, p. 645).

The Webster English Dictionary defines the term 'hedonic' as 'something relating to or characterized by pleasure' (Merriam-Webster 2012). In a retail setting, hedonic shopping motivation, "designates those facets of consumer behavior that relate to multisensory, fantasy and emotive aspects of consumption' (Hirschman and Holbrook, 1982). Shoppers derive hedonic value from the fun and pleasure associated with the buying process and the immediate personal gratification derived from the emotional benefits and entertainment provided by the shopping experience (Arnold and Reynolds, 2003). Shopping in this sense becomes a search for happiness, fantasy, awakening, sensuality and enjoyment (Holbrook and Hirschman, 1982) and the purchase of goods becomes secondary to the experience of shopping as people buy so they can shop, not shop so they can buy (Babin, et al., 1994).

\section{Related Literature and Hypotheses}

The review of the literature specific to shopping motivation is divided into three parts. Part one dwells on shoppers' taxonomies; part two discusses the antecedents and outcomes of shopping motivation, and part three provides a brief account of some research that was done in countries whose economic and socio-cultural context parallels that of Bahrain.

Regarding shoppers' taxonomies and motivation four important academic contributions are particularly relevant to the purpose and objectives of the study described here. The first was an exploratory study by Tauber (1972) in which he sought to answer two important questions. Do people shop simply to make purchases? Are shopping trips motivated by considerations that are unrelated to an actual purchase? (1972, p. 46). Using in-depth interviews, Tauber asked his respondents to recall their most recent shopping trip to discuss their activities while shopping, and what they enjoyed about the trip. Answers were, then, categorized into two hypothesized shopping motives; personal or social. Personal motives include; role playing, diversion, self-gratification, physical activity and sensory stimulation. Social motives refer to social experiences outside the home; communication with others; peer group attractions; and status and authority. Thus, for retailers, "the ability to gain a distinct competitive advantage may depend on catering to shopping motives that are not product related" (Tauber, 1972, p 49). Westbrook and Black (1985) sought to verify Tauber's work among a sample of female shoppers in Arizona, US. Seven dimensions of shopping motivations were suggested: anticipated utility (the benefits provided by the product acquired via shopping), role enactment (identifying and assuming culturally prescribed roles), negotiation (seeking economic advantage via bargaining), choice optimization (searching for and securing precisely the right products), affiliation (with others directly or indirectly), power and authority (attainment of elevated social position), and stimulation (seeking novel and interesting stimuli). In the thrid study, Babin et al. (1994) developed a scale that captures consumers' evaluations of a shopping experience along two important dimensions: utilitarian and hedonic value. The utilitarian outcome results from some type of conscious pursuit of an intended consequence (Babin et al., 1994, p. 645). Often this means the purchase of a product in an efficient and deliberate manner. Hedonic shopping value reflects the distinction between performing an act 'to get something' as opposed to doing it because 'you love it' (Triandis, 1977; Babin et al. 1994). It is the 'festive', ludic, or epicurean side of shopping and the 'fun' and 'playfulness' that accompany a shopping trip (Sherry, 1990; Holbrook and Hirschman, 1982; Babin et al., 1994). Concentrating only on hedonic motivation, Arnolds and Reynolds (2003) came up with a comprehensive inventory of consumers shopping motivation; mainly adventure, gratification, role, value, social and idea shopping motivation. These reflect five shopper segments; namely the 'minimalists', 'the gatherers', 'the providers', 'the 'enthusiasts', and the' traditionalists'.

To put the shopping motivation construct in perspective, a considerable number of studies have tried to identify its main antecedents. The bulk of these studies related the concept to shoppers' demographic characteristics. These include age, gender, income, education, marital status, ethnicity ...etc. The common thread that linked all these studies together seems to be that; the shopping experience, enjoyment, motivation vary markedly among different demographic groups (Otnes and McGrath, 2001; Cox et al. 2005; Noble et al., 2006; Michon, 2007; Carpenter, 2008; Carpenter and Broshdahl, 2011). Others added more variables to the demographic explanatory model. For example, in a study that explored adolescent girls mall experience in the US, Haytko and Baker (2004) concluded that participants characteristics, situational factors, mall characteristics and mall choice all 
combined to determine young girls mall's experience. Michon and Chebat (2004) investigated shopping values and mall activities in a bicultural setting to test for differences among French Canadian and English Canadian shoppers. French Canadian shoppers scored significantly higher than did English Canadian shoppers on both hedonic and utilitarian scales. Jones et al. (2010) explored the impact of culture on the perceptions and values of a sample of American and Australian customers. According to the authors, culture appeared to have a strong moderating effect on shopping satisfaction; one that is greater for Australian than for Americans. The American consumers, the writers explained, have been in advanced retail settings with greater variety of readily available goods much longer than Australians. As such Americans derive little pleasure in acquiring the product (utilitarian value) or drive less satisfaction from sheer act of shopping (hedonic value).

Other studies looked upon shopping motivation as an intervening variable that impacts a host of retail outcomes. For instance, Reynolds and Arnolds (2006) addressed the question of how hedonic and utilitarian shopping values differ in their impact of several retail outcomes. Both hedonic and utilitarian shopping values were found to influence satisfaction, positive word of mouth, loyalty, repatronage intentions, and repatronage anticipations. Kim \& Kim (2008) also reported shopping enjoyment to have a differential influence on two shopping modes; browsing and bargain hunting. Carpenter (2009), likewise, underlined how utilitarian and hedonic shopping values on one hand, are related to satisfaction and loyalty on the other. As utilitarian and hedonic shopping values increase, he noted, satisfaction also increases. Satisfaction, in turn, is found to positively influence attitudinal loyalty which also bears positively on word of mouth communication and share of purchases.

Very little research addressed shopping values in the Gulf region. One rare contribution in this regard, however, is a research paper that investigated reasons consumers go shopping in Doha, Qatar (Jamal et al., 2006). Six homogenous shopping groups with different emphasis on specific shopping reasons were identified. These are 'gratification seeking', 'social shopping', 'high quality seeking', 'confused by over choice', 'value seeking' and 'brand conscious' customers. The authors, then, examined similarities and differences among the various clusters of customers by profiling them on demographic and ethnic group membership. A second study tried to determine shopping mall attractiveness factors from the shoppers' perspective in the UAE (El-Adly, 2007). Six mall attractiveness factors were revealed. Namely, comfort, entertainment, diversity, mall essence, convenience, and luxury. These, in turn, correspond to three mall shopper segments; the 'relaxed shoppers', 'demanding shoppers', and 'pragmatic shoppers'. Each segment was then profiled in terms of mall attractiveness, demographics and shopping behavior.

\subsection{Hedonic Shopping Motivation}

As indicated above, hedonic shopping motivation has been defined as those facets of behavior that relate to the multisensory, fantasy and emotional aspects of consumption (Hirschman and Holbrook, 1982; Arnold and Reynolds, 2003). The shoppers here enjoy shopping for its own sake often 'expressing excitement, increased arousal, and a deep sense of enjoyment' (Babin et al. 1994) emanating from the experience itself independent and separate from the acquisition of the products they buy. Psychologists maintain that human behavior is driven in certain cases by a need for novelty and sensation-seeking ... A personality trait defined by the search for experiences and feelings that are varied, novel, complex and intense... the pursuit of unfamiliar and complex environmental stimuli (Schifman and Kanook, 2011). The shopping mall in the Gulf region is a recent phenomenon yet to become an integral fixture of the region's culture. It seems logical, therefore, to expect the novelty and newness of these modern retail habitats anchoring international hypermarkets, household brand names, themed cafes, and recreational facilities coupled with various shopping festivals/events to impact the goals and priorities respondents seek while they shop. These priorities and goals, in turn, are expected to be mainly hedonic in nature. Hence, the proportion of respondents who seek hedonic value from their shopping experiences is expected to be higher than the proportion of those who look for utilitarian goals.

H 1: The Bahraini shopper is expected to stress the hedonic aspects of shopping more than the utilitarian facets of it.

\subsection{Social Shopping}

An important facet of hedonic shopping motivation is social. Humans are regarded as being altruistic, cohesive, and seeking acceptance and affection in interpersonal relationships (McGuire, 1974; Arnolds \& Renolds, 2003). Shopping is an activity that is always done in proximity to others (Cox et al., 2005). In this sense, it provides an important domain in which such urge is satisfied. Many people treasure the time spent shopping with friends and family members. This is labeled 'social shopping,' which refers to the enjoyment of shopping with friends and family, socializing while shopping, and bonding with others while shopping (Arnolds and Reynolds, 2003). To some writers this is usually the main reason for consumers to go shopping (Dawson et al., 1990). In view of 
the hot and humid climate in the Gulf region, the long summer days and the lack of convenient venues in which people can mingle and socialize, modern shopping malls with their controlled air-conditioned atmosphere provide secure and physically comfortable environments in which shoppers can get together and relate to each other. This would lead us to the second hypothesis:

H2: The Bahraini shopper is expected to stress the social aspects of shopping more than the utilitarian parts of it.

\subsection{The Impact of the Demographic Variables on the Shopping Experience}

Within the context of the previous two hypotheses the sample's demographic characteristics are expected to significantly discriminate among respondents. A decent body of literature exists that seems to suggest that the individual characteristics of consumers would shape, color and constrain their shopping experience (Dholakia and Uusitalo, 2002; Carpenter, 2008). Among the variables that are known to have an impact in this respect are: age, gender, marital status, education, ethnicity ... etc. If these factors were found to impact respondents' experience of shopping in this study, then this can only be understood and explained within the social, cultural and climatic contexts of the shoppers under study.

\subsubsection{Gender}

Gender remains to be an important factor in understanding shopping behavior (Dholakis and Uusituo, (2002); Jamal et al., (2006); Noble et al., (2006); Michon, (2007). The bottom line here seems to be that, because of biological, psychological, and sociological reasons, male and female shoppers do perceive their shopping experience differently (Noble et al., 2006). Campbell (1997), for instance, had noted long time ago that men are more inclined to see shopping as work and purely purchase-driven whilst women are likely to perceive it as leisure and a pleasure-seeking activity. Since shopping can be a context which is hedonically rich and interpersonally rewarding; females are more likely than men to seek out fulfillment from shopping (1997, p. 167). This leads, therefore, to the expectation that:

H3: The Bahraini female shopper is more hedonistic than the male shopper.

Socially, women view themselves as connected to others guided mainly by some communal concerns. This is consistent with their interdependent self-construal (Cross and Madison, 1997). When they act their behavior is guided by the desire to engage in and maintain interpersonal affiliations. Shopping and shopping contexts offer women the opportunity to socially interact with and connect to other family members, relatives and friends (Noble et al., 2006). Given such a premise, it is logical to assume that:

H4: The Bahraini female shopper is more likely to stress social shopping than the Bahraini male shopper.

Value shopping i.e. shopping for sales, looking for discounts, hunting for bargains can provide increased involvement and excitement among customers (Babin et al., 1994). Shopping here is looked upon as if it is a 'challenge' to conquer or a game to be won (Arnold and Reynolds, 2003). The rationale behind this idea is that 'humans are believed to be competitive achievers, seeking success and admiration and striving to develop their full potential in order to enhance their self-images (McGuire's, 1974). This is expected to be more prominent among female shoppers.

H5: Value shopping is expected to be more pronounced among female than male shoppers.

\subsubsection{Age}

Compared to the other individual characteristics, age assumes an added weight as an explanatory variable of shopping behavior (Carpenter, 2008; Baltas et al., 2010). A number of studies seem to indicate that shopping behavior is age related; that people in different age groups tend to differ in how they view and perceive their shopping experience (Sorce et al., 2005; Dholakia and Uusitalo, 2002). However, the literature seems to be inconclusive vis-à-vis the direction and magnitude of such relationship. While a number of studies had found that older more than younger shoppers are more prone to seek social interactions and leisure from their shopping experiences (Krogaonkar \& Wolin, 1999), others point to the opposite; younger shoppers are more hedonistic in their shopping than older ones (Joines et al., 2003). The present study should be seen as a contribution to this controversy; i.e. the impact of age on shopping motivation. The population within the Gulf region is largely young. Young people are expected to shop more, spend more, and make more trips to the mall than shoppers in other age group (Haytako \& Baker, 2004). So the expectation is that:

H 6: Young shoppers are likely to stress the hedonistic aspects of shopping more than older ones.

H7: Social hopping is expected to be more pronounced among young shoppers rather than older ones. 


\subsubsection{Nationality}

Shopping values and orientations are in part consequences of culture and ethnicity (Rexta \& Kingshott, 2001). Contrary to the melting-pot hypothesis (D’Innocenzo \& Sinefman, 1992) ethnic identities seem to be constructed and accentuated through consumption rather than production. People tend to reinforce -not relinquish- their identification by shopping (Halter, 2002). In this respect shopping appears to play an important social role in minorities' shopping. It is logical, therefore, to assume that for the non-Bahrainis shopping habitats may provide important venues to affirm their cultural identity and strengthen their social ties with their fellow countrymen (Michon \& Chebat, 2004)). Hence, social shopping is expected to be more important to the non-Bahraini than the Bahraini shopper.

H 8: The non-Bahraini shopper is expected to stress social shopping more than the Bahraini shopper.

Figure (1) provides a conceptualization of the main factors which are envisaged to bear on the respondents' shopping experience.

a. The Independent Factors
b.
the Gulf Region $\quad \sqrt[\begin{array}{c}\text { Intervening Variables } \\ \text { Demographic characteristics (age, } \\ \text { gender, marital status, nationality, } \\ \text { education) }\end{array}]{n}$

Figure 1. A theoretical explanatory model of shopping motivation in bahrain

\section{Methodology}

\subsection{Measures}

A rich line of research had, over the years, resulted in an array of measurements that trace shopping motivation. Prominent among these, is the hedonic-utilitarian dichotomy developed by Babin et al. (1994); and hedonic motivation scale by Arnold \& Reynolds (2003). By and large the two measures utilized a Likert-scaled format in which respondents indicate the extent of their agreement or disagreement to specific statements about their shopping experience. The scale became the main research instrument for the data collection process. Eighteen statements were used. These addressed a number of the respondents' shopping aspects; namely hedonic, social, gratification seeking, role playing, value shopping and utilitarian motivation. Two versions of the questionnaire were developed; one in Arabic and the other in English. Because Bahrainis are mostly bilingual, respondents were to choose as to which version they prefer.

\subsection{Factor Analysis}

The large number of statements used to trace the different facets of shopping motivation among the sample members resulted in too-many variables to deal with in the data analysis stage. To assess and select the items most relevant to the study's hypotheses, two statistics were used; factor analysis and Cronbach reliability test. Factor analysis is used here to simplify the data analysis process by limiting the analysis to a few salient factors that account most to the variance within the model. A principle component analysis was the tool used for the factor extraction. The screening plot and the eigenvalue criterion point to a four factor solution that accounts for more than $60 \%$ of the total variance explained. These factors were retained for further analysis. All in all, 12 of the 18 statements loaded significantly on the four factors extracted. They were labeled respectively 'hedonic (27.7\%)', 'utilitarian (12.8\%)', 'value shopping' (11.2\%)' and 'social shopping' (9\%). The remaining six statements loaded poorly on any of the factors alluded to above and were therefore eliminated (i.e. their eigenvalues were less than .40). They include one statement from the hedonic motivation, two statements from the utilitarian motivation, the two statements of role shopping, and one from social shopping (Table 1).

Next, the factors were checked for internal consistency. This refers to the degree to which the items that make up the scale all measure the same underlying construct (Pallant, 2011). Cronbach's reliability coefficients were calculated for the items within each construct. The Alpha estimates of the four factors were .76, -.76, .81, and .62, respectively. As the figures reflect, the first three constructs satisfied the recommended internal consistency coefficient. The fourth is slightly lower. In view of the fact that this is an exploratory study carried out in a different socio-cultural milieu, the coefficient is deemed acceptable. 
Table 1. Shopping motivation scale: factor analysis results

\begin{tabular}{lc}
\hline Scale Item & Factor loading \\
\hline Factor One: Hedonic shopping & .612 \\
He1: To me my last shopping trip was truly a joy. & .688 \\
He2: Compared to other things I could have done, the time I spent shopping was truly enjoyable. & .584 \\
He3: I enjoyed my last shopping trip for its own sake, not just for the items I have purchased. & .533 \\
He4: I go shopping not because I have to, but because I want to. & .764 \\
He5: When I am in a down mood, I go shopping to make me feel better. & .791 \\
He6:To me, shopping is a way to relieve stress and forget my daily problems & .76 \\
Cronbach alpha & .811 \\
Factor two: Utilitarian shopping & .747 \\
Util.1: While shopping, I found just the item(s) I was looking for. & .76 \\
Util.2: I enjoy the hunt for discounts and special offers when shopping. & \\
Cronbach alpha & .931 \\
Factor three: Value shopping & .886 \\
Val1: More often than not, I go shopping when there are sales. & .81 \\
Val2: I enjoy the hunt for discounts and special offers when shopping. & .814 \\
Cronbach alpha & .836 \\
Factor four: Social shopping & .62 \\
S1: I enjoy shopping more when I am in the company of friends and family & \\
S2: Shopping with others is a bonding experience. & \\
Cronbach alpha &
\end{tabular}

\subsection{The Sample}

Realizing the study's objectives required the collection of information from a sample of Bahraini shoppers. This process is done in two stages. Stage one involved a non-probability snowball sample. Self-administered questionnaires were distributed to a group of volunteers that included students, staff members, and employees within the University of Bahrain. This group, in turn, became a referral to friends, family members, neighbors and acquaintances. Half of the questionnaires were distributed this way. The second stage of the field work constituted more or less a mall-intercept survey. Three malls were randomly selected as suitable venues for the intercept; namely, the Lulu Center and the Oasis mall in Al-Riffaa City and the Bahrain mall. A main concern while selecting members of both samples was to ensure an adequate representation of the population of the study. The data collection process went on throughout the month of June, 2012. In total, 400 questionnaires were distributed. 287 filled-in questionnaires were eventually returned (71.8\% response rate). The realized sample constitutes a decent cross-section of the Bahraini society as evident in the sample characteristics. $60 \%$ of the sample is females, $40 \%$ males, $51 \%$ singles, $41 \%$ married, and $31 \%$ non-Bahrainis compared to $69 \%$ Bahrainis. The majority of the sample is under the age of $30(61 \%)$, and $63 \%$ of the sample are college graduates.

\subsection{Statistics}

The decision on what statistics is appropriate for the data analysis process is guided by two main considerations: the objectives of the study and the nature of the data at hand. The study seeks to shed light on the shopping motivation of a sample of customers in the kingdom of Bahrain by testing specific hypotheses in this regard. The nature of data collected, on the other hand, bears heavily on the choice of statistics to make it intelligible. The data is largely nominal and ordinal. As such its linearity and normality cannot be safely assumed.

Bearing this in mind, Frequencies and percentages were used to highlight the sample characteristics. H1 and H2 were verified using simple descriptive statistics; namely frequencies, measures of central tendency, histograms, cross-tabulations and measures of skewness and kurtosis. Regarding hypotheses 2-9, two nonparametric statistics were deemed appropriate to uncover differences among groups in their shopping motivation; the Mann-Whitney and the Kruskal Wallis Tests. For variables with two independent groups like gender and nationality, the Mann-Whitney Test (an alternative to the T-Test) is used. For others that contain a minimum of three independent groups like age, education and marital status a Kruskal Wallis Test - a nonparametric alternative to a one-way between-groups analysis of variance- is utilized. The Mean Rank statistics in both tests describes the direction of the differences (Pallant, 2011). 


\section{Analysis and Results}

The analysis of the data collected uncovered the following results:

1) As said earlier, the hot and humid climate of the Gulf region and the lack of alternative venues for people to socialize and entertain themselves, have colored their perception of the shopping mall. The modern shopping habitats are increasingly looked upon as recreational and social milieus that fulfill to shoppers a host of benefits other than buying. This led to expect that, shoppers in the Gulf region would reflect the hedonic and social aspects of their shopping experience more than the utilitarian facets of it. Statistics confirm this expectation. The hedonic and social facets of shopping had both higher means levels compared to the utilitarian reasons of shopping ( $X=3.75, X=3.6$ on 1-5 scale, significantly higher than the utilitarian shopping mean $X=2.6$ ). Overall, $66 \%$ and $60 \%$ of respondents reported that they either agree or strongly agree with statements that reflect hedonic or social reasons for shopping, respectively. Figures $2 \& 3$ show negative skew values indicating a clustering of scores at the high end (right-hand side of the graph) signalizing that the majority of the sample is in agreement with statements relating to social and hedonic shopping. The low skew value (close to zero) and the positive kurtosis indicate that the distribution of utilitarian shopping scores is rather peaked (clustered in the centre) approaching a normal distribution of the sample answers (figure 4) (Pallant, 2011).

2) Shopping motivation is expected to be markedly different between the male and the female shopper. The results strongly support this notion. As the Mann-Whitney Test reveals there is a statistically significant difference between the two sexes in their perception of the different facets of their shopping experience. $(U=6236 ; p=0.00)$. The female shopper recorded a higher median value than the male shopper indicating that the Bahraini female shopper is more hedonistic when shopping than the male shopper (Female MD= 165; Male $\mathrm{MD}=122$ ). Likewise, The Test confirms the hypothesis that there are also significant differences between the two groups in social shopping $(\mathrm{U}=7733 \mathrm{p}=.001)$. As evident from the median score, the enjoyment of social shopping appears to be more pronounced among female shoppers than male shoppers (female $\mathrm{MD}=156.6$; male $\mathrm{MD}=125.25$ ). Another area in which male and female shoppers differ significantly is 'value shopping' as reflected by the Mann-Whitney statistics ( $\mathrm{U}=8491 ; \mathrm{p}=.038$ ). The female shopper is more likely to go shopping when there are 'sales' and to enjoy the hunt for 'discounts and special offers' than the male shopper.

3) The data also suggest that the shopping experience among different age groups is significantly different. A Kruscal Wallis Test indicates that this is the case; that young shoppers are more likely, it appears, to seek and enjoy the hedonics aspects of shopping than older ones (Chi Square $=14.4 ; \mathrm{df}=5 ; \mathrm{p}=.014$ ). Likewise, the Test also revealed significant differences among the different age groups in their social shopping (Chi-square=14.4, df=5 Sig. $=.014, \mathrm{MR}=163$ ). Younger shoppers are more likely to shop for social reasons than older customers (Chi-square $=17.9, \mathrm{df} .=5$, Sig. $=.003$, MR $=163$ ).

Contrary to expectations, the results did not support hypothesis (8). Nationality did not contribute to any statistically significant differences between Bahrainis and no-Bahrainis in their hedonic $(U=7846, p=0.159)$; social $(\mathrm{U}=8111 \mathrm{p}=.312)$; value $(\mathrm{U}=9096, \mathrm{p}=.256)$; or utilitarian shopping $(\mathrm{U}=8313, \mathrm{p}=.570)$. This result can be explained by the fact that the hedonic and social reasons for shopping were so pervasive among sample members that they nullified any impact the nationality factor might have had on the shopping experience of respondents. The distribution of the sample's answers to questions relating to utilitarian shopping seems to cluster around the centre (peaked) of distribution which also led to the failure of the variable in question to account for any significant differences among respondents. 


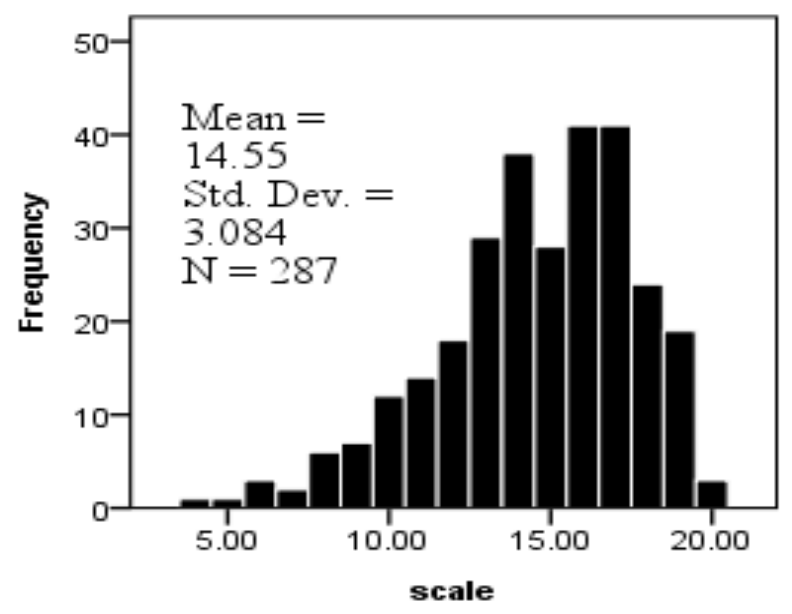

Figure 2. Hedonic motivation

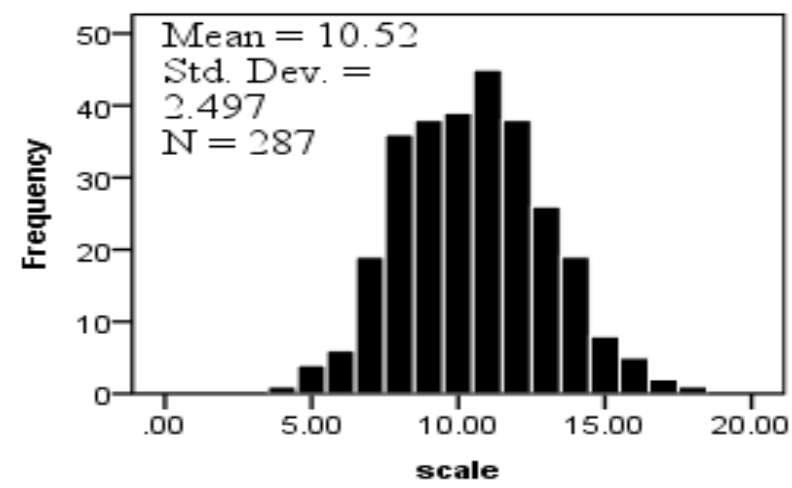

Figure 3. Utilitarian motivation

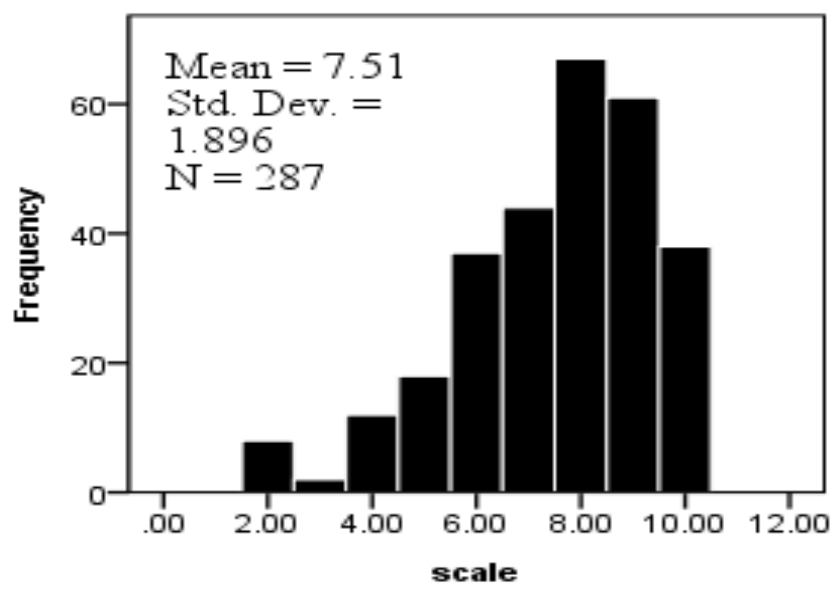

Figure 4. Social motivation

\section{Conclusions and Discussion}

The retail sector of the GCC countries is, in every sense of the word, an expanding universe. Within the last twenty years new malls, hypermarkets, department stores, supermarkets, discount and specialty stores seem to pop up on the retail scene in record times to become, today, a constant feature of the region's landscape. 
The emergence of these modern retail habitats is destined to impact customers' shopping experience. The purpose of this research paper is to test the thesis that shoppers in the Gulf region would value the hedonic and social aspects of their shopping more than the utilitarian aspects of it. The results obtained confirm this expectation. The majority of the sample members seem, as the data reflect, to shop for two main reasons; hedonic and social. Two plausible scenarios explain these findings: the newness and novelty of the mall as a modern shopping habitat and the harsh climatic conditions of the region; the searing heat and high humidity.

Individual's behavior is known, in certain cases, to be driven by novelty and sensation-seeking; a craving to 'seek varied, complex and intensive sensations' (Zukerman, 1994). The modern shopping mall bears all the hallmarks of a novel environment; mainly novelty, surprisingness, change, ambiguity, and uncertainty (Berlyne, 1963). These properties are expected to motivate the mall visitors to engage in exploratory behavior to reduce arousal (Rajou \& Venkatesen, 1980). Shopping trips become, in this sense, a journey to explore, 'a pursuit for physical activities that are exciting and unusual ... an experience that stimulates the mind and senses...a pursuit of unfamiliar and complex environmental stimuli' (Zukerman, 2007).

The weather in the Gulf region is known for its long summer days, intense desert heat and high humidity. Prior to the introduction of the modern shopping mall these extreme weather conditions occasionally interfere with consumer's shopping. At the very least such weather keeps them at home, or negatively impacts their moods (Murry et al., 2010). People find it difficult and physically demanding to shop in the conventional open-to-air marketplaces in these conditions. The advent of the modern shopping habitats in the area coupled with their enclosed, air-conditioned and cozy atmosphere, and the elaborate attractions they offer have to a large extent neutralized these unfavorable weather conditions. Thus, a visit to the mall has therefore become the shopper's preferred way of escaping the intense desert heat. Worth mentioning here, perhaps, is a study that addressed whether the mall culture is gaining acceptance among Indian consumers in the city of Surat, India. The city's weather closely resembles that of the Gulf region. An overwhelming majority of shoppers, who participated in the study, mentioned air-conditioning as the chief reason as to why they have shifted their preference to mall-shopping. Air conditioning, it appears, removes the exhaustion and fatigue with shopping and transforms it into a pleasurable experience (Kavita, 2012).

Viewed within the context of the extant literature these findings seem consistent with a number of studies which were carried out in transitional economies. For instance, in a study reported earlier, Jamal et al. (2006b) found out that the largest segment among a sample of Qatari shoppers is a group labeled the 'escapists'; who reported their primarily shopping motivation to be gratification and hedonism. These shoppers view their shopping as an escape mechanism to get their minds off their problems and as a way for relieving stress and alleviating negative moods. Similarly, Nguyen (2007) points to the important role hedonic shopping motivation and supermarket attributes play in explaining customer loyalty among Vietnamese shoppers. In a somewhat different line of inquiry, Griffen et al. (2000) inject doubt into the expectation that American and Russian consumers shopping values would be markedly different given the relatively limited shopping environments provided to Russian consumers. To the contrary, Russian consumers reports for hedonic values or the pleasure derived from shopping, are similar to those in the U.S. Drawing on the adaptation level theory, the authors argued that the Russian consumers managed to adapt to these adverse economic circumstances and derived high amounts of pleasure from shopping comparable to those of their American counterparts.

The respondents also value the social opportunities that a shopping trip presents. This feature of modern retailing is widely reported in the literature to be an important dimension of the shopping experience (Tauber, 1972; Westbrook and Black, 1985; Babin et al. 1994; Arnold and Reynolds, 2003; Cardoso and Ointo, 2010). A rare exception, however, is a study by Cox et al. (2005) in which they advocated that social shopping is a myth. To these writers although shopping is always done in the proximity of other people, it is essentially a private experience that occurs in a public setting (Cox et al. 2005; Falk and Campbell, 1997).

An understanding of the sample's shopping experience entails exploring how it relates to the sample's demographic characteristics. Two variables stand out in this regard; gender and age. The Mann-Whitney Test revealed significant statistical differences between the two sexes in their shopping attitudes. The Bahraini female shopper is more hedonistic, more likely to engage in value-shopping, and more likely to shop for social reasons than her male counterpart.

These findings are in line with most of the research findings that addressed the gender-shopping motivation question (Dholakis \& Uusituo, 2002; Carpenter, 2007). What makes these findings different, however, is a cultural interpretation related mainly to women social roles in Arab societies. In explaining similar results to those outlined above, Jamal et al. (2006) note, 'men in traditional Arab societies mostly go out to work whereas 
women tend to stay home taking care of children and domestic chores. This, along with the harsh desert weather during most parts of the year, might have a negative impact on the mood of the female consumer, who, therefore, perceive shopping as an alternative (to) forget the daily routines and indulge in shopping related social experiences outside their homes' (2006, p. 76).

An important demographic variable that also differentiated among respondents is age. The Kruskal Wallis Test revealed significant statistical differences among different age cohorts vis-à-vis their shopping orientations. Younger shoppers were found to be more hedonistic and seek more social benefits from shopping than older ones. On the face of it, these results seem logical as young shoppers are more likely to engage in browsing and exploratory shopping behavior than old ones. These findings corroborate similar results which were reported in earlier studies (Dholakia \& Uusito, 2002; Korgaonkar \& Wolin, 1999; Sorce et al., 2005).

Interestingly, however, there were no significant differences among respondents that can be attributed to the nationality factor (ethnicity). Non-Bahrainis were expected to accentuate their ethnic identity via shopping, i.e. they would use the shopping trip to interact with and relate to their fellow countrymen. As turned out, this was not the case. These results conflict an established line of research that view the ethnicity construct as an important variable to help explain variance in shopping motivation (Holbrook and Hirschman, 1982; Rexha \& Kingshott, 2001; Halter, 2002).

\section{Implications and Directions for Future Research}

These results raise some interesting implications: First: Shopping in the Gulf region is largely driven by two main factors: the novelty of the shopping mall as a modern retail habitat and the hot and humid weather of the gulf region. As the novelty of the mall wears out and the retail scene becomes more crowded, the management of these malls will face huge challenges to come up with new strategies in order to create a different, more family-oriented, and more varied and entertaining shopping experience (Howard, 2007). Fun must be at the heart of mall value proposition and shopping is regarded as part of the experience and not the whole of it (Berry et al., 1997; Howard, 2007). Second: Mall shopping in the Gulf region is gradually becoming a culture embraced by nearly everyone in society; young, old, male, female, married, single, college graduate or a school leaver. A defining feature of this new culture has to be the realization that the modern mall is not only a shopping hub but social as well. In it people seek to satisfy many needs including their social needs. Retail management must see to it that these social needs are catered for by creating a mall environment loaded with opportunities for social interactions and affiliations. Third: In this study, the assumption is made that the Bahraini shopper represents those in other GCC countries. It is true that there are more similarities than differences between Bahrain and other countries in the Gulf region, nevertheless, differences do exit. This is both a limitation and suggestion for future research. There is, therefore, a need for a much wider cross-cultural study that would address shopping motivation in all GCC countries in order to identify the similarities and differences among shoppers pertaining to their shopping experience in the region. Fourth: An underlying theme mentioned frequently here, is that the weather conditions within the gulf region, remain an important factor that prompt people to the mall. A logical question may arise: given such conditions, could it be possible that one day online shopping may prove to be the solution to the problem; an alternative to mall shopping? As the online shopping industry matures overtime; there is definitely a need for research to see how mall and online shopping in the region compare in this respect.

\section{Acknowledgement}

Sponsored by the Deanship of the College of Scientific Research, University of Bahrain.

\section{References}

Alpen Capital, A. (2011). GCC Retail Industry, UAE.

Arnold, M. J., \& Kristy, E. R. (2003). Hedonic Shopping Motivations. Journal of Retailing, 79(2), 77-95. http://dx.doi.org/10.1016/S0022-4359(03)00007-1

Babin, B. J., William, R. D., \& Mitch, G. (1994). Work and/or Fun: Measuring Hedonic and Utilitarian Shopping Value. Journal of Consumer Research, 20(March), 644-56. http://dx.doi.org/10.1086/209376

Baltas, G. et.al. (2010). The Role of Customer Factors in Multiple Store Patronage: A Cost-Benefit Approach. Journal of Retailing, 86(1), 37-50. http://dx.doi.org/10.1016/j.jretai.2010.01.005

Batra, R., \& Ahtola, O. T. (1990). Measuring the hedonic and utilitarian sources of consumer attitudes.

Batra, R., \& Indrajit, S. (2000). Consumer-Level Factors Moderating the Success of Private Label Brands. Journal of Retailing, 76(2), 175-91. http://dx.doi.org/10.1016/S0022-4359(00)00027-0 
Batra, R., \& Olli, T. A. (1991). Measuring the Hedonic and utilitarian Sources of Consumers attitudes. Marketing Letters, 2(April), 159-170. http://dx.doi.org/10.1007/BF00436035

Berlyne, D. E. (1960). Conflict, Arousal, and Curiosity. New York: McGraw-Hill. http://dx.doi.org/10.1037/11164-000

Berlyne, D. E. (1970). Novelty, Complexity, and Hedonic Value. Perception and Psychophysics, 8, 279-286. http://dx.doi.org/10.3758/BF03212593

Campbell, C. S. (1997). Shopping Pleasure and the Sex War. In Falk P., \& Campbell, C. (Eds.), the Shopping Experience. London: Sage. http://dx.doi.org/10.1037/11164-000

Carpenter, M. J. (2008). Demographic and patronage motives of supercenter shoppers in the United States. International Journal of Retail and Distribution Management, 36(1), 5-16. http://dx.doi.org/10.1108/09590550810846965

Carpenter, M. J. et al. (2009). Utilitarian and hedonic value in US discount sector. Journal of Retailing and Consumer Services, 16, 68-74. http://dx.doi.org/10.1016/j.jretconser.2008.10.002

Chebat, J. C., Michon, R. (2003). Impact of ambient odors on mall shoppers' emotions, cognition, and spending: A test of competitive casual theories. Journal of Business Research, 56, 529-539. http://dx.doi.org/10.1016/S0148-2963(01)00247-8

Cox, A. D., Cox, D., \& Anderson, R. D. (2005). Reassessing the pleasures of store shopping. Journal of Business Research, 58(3), 250-259. http://dx.doi.org/10.1016/S0148-2963(03)00160-7

Cross, S. E., \& Laura, M. (1997). Models of the Self: Self-Construals and Gender. Psychological Bulletin, 122(1), 5-37. http://dx.doi.org/10.1037/0033-2909.122.1.5

D’Innocezo, M., \& Jsel, P. S. (1992). Immigration and Ethnicity: American Society_ "Melting Pot" or "Salad Bowel”. West Port, CT: Greenwood Press.

Dawson, S., Peter, H. B., \& Nancy, M. R. (1990). Shopping Motives, Emotional States, and Retail Outcomes. Journal of Retailing, 66(Winter), 408-27.

Dholakia, R., \& Uusitalo. (2002). Switching to electronic Stores: Consumer Characteristics and the perception of Shopping benefits.

Dholakia, R. (1999). Going shopping: key determinants of shopping behaviors and motivations. International Journal of Retail \& Distribution Management, 27(4), 154-165. http://dx.doi.org/10.1108/09590559910268499

El-Adley, M. I. (2007). Shopping Malls Attractiveness. International Journal of Retail and Distribution, 35(11), 936-950. http://dx.doi.org/10.1108/09590550710828245

Griffen, M. et al. (200). Shopping values of Russian consumers: The impact of habituation theory in a developing economy. Journal of Retailing, 76(1), 33-52. http://dx.doi.org/10.1016/S0022-4359(99)00025-1

Griffin, M., Babin, B., \& Modianos, D. (2000). Shopping values of Russian consumers: the impact of habituation in a developing economy. Journal of Retailing, 76(1), 33-52.

Halter, M. (2002). Shopping for Identity: The marketing of Ethnicity. Scholcken, Books. New York.

Haytko, D. L., Baker, J. (2004). It's all at the mall: exploring adolescent girls' experiences. Journal of Retailing, 80, 67-83. http://dx.doi.org/10.1016/j.jretai.2004.01.005

Hirschman, E. C., \& Holbrook, M. B. (1982). Hedonic consumption: emerging concepts, methods and propositions. Journal of Marketing, 46, 92-101. http://dx.doi.org/10.2307/1251707

Holbrook, Morris, B. (1986). Emotion in the Consumption Experience: Toward a New Model of the Human Consumer. In Robert, A. P. et al. (Eds.), The Role of Affect in Consumer behavior: Emerging Theories and Applications. Lexington, MA: Heath.

Howard, E. (2007). New shopping centers: is leisure the answer? International Journal of retail and Distribution Management, 35(8), 661-672. http://dx.doi.org/10.1108/09590550710758649

Huczynski, A. A., \& Buchanan. (2010). Organizational Behavior. London: FT.

Jamal, A. et al. (2006). Profiling Consumers: A study of Qatari consumers shopping motivations. Journal of Retailing and Consumer Services, 13, 67-80. http://dx.doi.org/10.1016/j.jretconser.2005.08.002

Jones, M., Kristy, E. R., \& Mark, J. A. (2006). Hedonic and Utilitarian Shopping Value: Investigating 
Differential Effects on Retail Out-comes. Journal of Business Research, 59(September), 974-81. http://dx.doi.org/10.1016/j.jbusres.2006.03.006

Kavita, K. A. (2012). Change in consumer behavior in Surat with introduction of mall. Indian Journal of Research in Finance and Marketing, 2(4).

Kim, E. Y., Kim, Y. K. (2005). The effects of ethnicity and gender on teens' mall shopping motivations. Clothing and Textiles Research Journal, 23, 65-77. http://dx.doi.org/10.1177/0887302X0502300201

Kim, H. Y., \& Kim, Y. K. (2008). Shopping Enjoyment and Store Shopping Modes: The Moderating Influence of Chronic Time pressure. Journal of Retailing and Consumer Services, 15, 410-419. http://dx.doi.org/10.1016/j.jretconser.2007.10.003

Koraonkar, P., \& Wolin, L. (1990). A multivariate analysis of web usage. Journal of Advertising Research, 38(1), 7-21.

Langrehr, F. W. (1991). Retail Shopping Mall Semiotics and Hedonic Consumption. Marketing Letters, 2(2), $159-70$.

McGuire, W. (1974). Psychological motives and communication .Gratification. In Blumer, J. F., \& Katz. (Eds.), The Uses of Mass Communication: Current Perspectives on Gratification Research (pp. 106-167). Beverly Hills: Sage.

Merriam-Webster. (2012). Retrieved from http://www.merriam-webster.com

Michon, J., \& Chebat, J. C. (2004). Cross-cultural malls shopping and habitats: A comparison between Englishand French-speaking Canadians. Journal of Business Research, 57, 883-892. http://dx.doi.org/10.1016/S0148-2963(02)00291-6

Murry, B. K. et al. (2010). The effect of Weather on Consumer Spending. Journal of Retailing and Consumer Services, 17, 512-520. http://dx.doi.org/10.1016/j.jretconser.2010.08.006

Neda, A., Kozma, A., Marti, G. P. (2006). Continuity of leisure participation from middle age to old age. The Journals of Gerontology, 61B, S340-S346.

Nguyen \& Tran, T. M. (2007). Hedonic shopping motivations, supermarket attributes, and shopper loyalty in transitional markets: Evidence from Vietnam. Asian Journal of Marketing and Logistics, 19(3), 227-229. http://dx.doi.org/10.1108/13555850710772914

Noble, S. M., Griffith, D. A., \& Adjei, M. T. (2006). Drivers of local merchant loyalty: understanding the influence of gender and shopping motives. Journal of Retailing, 82(3), 177-188. http://dx.doi.org/10.1016/j.jretai.2006.05.002

Noble, S. M., Haytko, D. L., Phillips, J. (2009). What drives college-age Generation Y consumers? Journal of Business Research, 62, 617-628. http://dx.doi.org/10.1016/j.jbusres.2008.01.020

Noble, S. M., David, A. G., \& Mavis, T. A. (2006). Drivers of Local Merchant Loyalty: Understanding the Influence of Gender and Shopping Motives. Journal of Retailing, 82(3), 177-88. http://dx.doi.org/10.1016/j.jretai.2006.05.002

Otnes, C., \& Mary, A. M. (2001). Perceptions and Realities of Male Shopping Behavior. Journal of Retailing, 77(1), 111-37. http://dx.doi.org/10.1016/S0022-4359(00)00047-6

Pallant, J. (2011). Spss surviaval manual: A step by step guide to data analysis using spss (4th ed.). Allen Unwin.

Puccinelli, N. M. et al. (2009). Customer Experience Management in Retailing: Understanding the Buying Process. Journal of Retailing, 85, 15-30. http://dx.doi.org/10.1016/j.jretai.2008.11.003

Raju, P. S., \& Venkatesen. (1980). Exploratory Behavior in the Consumer Context; A State of the Art Review. Advances in Consumer Research, 7, 258-263.

Ratneshwar, S., David, M., \& Cythia, H. (2000). The Why of Consumption, Contemporary Perspectives on Consumer Motives, Goals and desires. New York: Routledge. http://dx.doi.org/10.4324/9780203380338

Rexha, N. C., \& KIngshott, R. P. (2001). The Impact of Ethnic Identification Upon Consumer Behavior. European Advances in Consumer Research, 5, 327-333.

Riandis, H. C. (1997). Interpersonal Behavior. Moneterey CA: Brooks/Cole.

Schiffman, L. G., \& Kanuk, L. L. (2010). Consumer Behavior (10th ed.). Pearson, New Jersey. 
Sherry, J. F., McGrath, M. A., \& Levy, S. J. (1993). The dark side of the gift. Journal of Business Research, 28(3), 225-244. http://dx.doi.org/10.1016/0148-2963(93)90049-U

Sherry \& John, F., Jr. (1990). A Sociological Analysis of a Midwestern Flea Market. Journal of Consumer research, 17(June), 13-30. http://dx.doi.org/10.1086/208533

Sorce, P. et al. (2005). Attitudes and age differences in Online Buying. International Journal of Retail and Distribution Management, 33(2), 122-132. http://dx.doi.org/10.1108/09590550510581458

Tauber, E. M. (1972). Why do people shop? Journal of Marketing, 36, 46-59. http://dx.doi.org/10.2307/1250426

Westbrook, R. A., \& William, B. (1985). A Motivation-Based Shopper Typology. Journal of Retailing, 61(Spring), 78-103.

Xu, J., Shim, S., Lotz, S., \& Almeida, D. (2004). Ethnic identify, socialization factors, and culture-specific consumption behavior. Psychology \& Marketing, 21(2), 93-112. http://dx.doi.org/10.1002/mar.10117

Zukerman, M. (1964). Behavioral Expressions and Biosocial Bases of Sensation seeking. Cambridge University Press, New York.

Zukerman, M. (2007). Sensation and Risky Behavior. American Psychological Association, Washington, DC. http://dx.doi.org/10.1037/11555-000

\section{Copyrights}

Copyright for this article is retained by the author(s), with first publication rights granted to the journal.

This is an open-access article distributed under the terms and conditions of the Creative Commons Attribution license (http://creativecommons.org/licenses/by/3.0/). 